\title{
AFM study on amyloid peptide - graphene oxide assembly and its interaction with liposome
}

\author{
Received 3 April, 2015; Accepted 11 April, 2015 \\ Journal of Self-Assembly and Molecular Electronics, Vol. 3 (2015). \\ (C) 2015 River Publishers. All rights reserved
}

Yunpeng Cao ${ }^{1,2}$, Liguo Tao ${ }^{3}$, Jie Wang $^{1}$, Hüsnü Aslan ${ }^{4}$, Lei Liu ${ }^{1}$ and Mingdong

Dong $^{4 *}$

${ }^{1}$ Institue for Advanced Materials, Jiangsu University, China

${ }^{2}$ School of Materials Science and Engineering, Jiangsu University, China

${ }^{3}$ School of Food and Biological Engineering, Jiangsu University, China

${ }^{4}$ Interdisciplinary Nanoscience Center (iNANO), Aarhus University, 8000 Aarhus C (Denmark)

Correspondence should be addressed to: dong@inano.au.dk.

\begin{abstract}
The interaction between amyloid peptides and membrane is a broad research topic due to the variety of biological events occurring, such as the membrane disruption related pathogenesis of amyloid diseases or the toxicity of peptide materials. Amyloid peptides have many structural forms, it is therefore important to explore the interactions between the membrane and assemblies of amyloid peptides, and to find ways to control these interactions. Herein, we utilized atomic force microscopy (AFM) and circular dichroism spectra to explore the modulating effect of Graphene Oxide (GO) on amyloid peptide assembly. In addition, the interaction between liposome samples and amyloid peptide assembly modulated by GO was investigated. It is achieved that the membrane disruption of amyloid peptide aggregates can be fine-tuned by tweaking the GO concentration. The findings in this work provide a better understanding of amyloid peptide and membrane interactions and how it can be tuned.
\end{abstract}

\section{Introduction}

Biophysical explorations and mechanistic researches with simplified model membrane systems could contribute to the fundamental understanding of the interactions between amyloid-forming proteins and membranes ${ }^{1}$. Amyloid peptides 
can assemble into different ordered or disordered forms such as pores, fibers and aggregates. In intermediate stages, it is often possible to see a mixture of different forms. With its changing structure, the peptides' toxicity and role in pathogenesis also changes. Therefore, it is of utmost importance to study the stages of morphological transformation and how it can be controlled.

Beta amyloid peptide $(A \beta)$ is a typical amyloid peptide derived from the amyloid precursor protein (APP) by proteolysis ${ }^{5}$. The fragments of $A \beta^{6}$ for instance, $A \beta 28^{7}$, $\mathrm{A} \beta 25-35^{8}$ and $\mathrm{A} \beta 10-20^{9}$, form aggregates that were proved to have the ability to interact with the membrane. Recently $A \beta 33-42$ as a significant fragment of the transmembrane domain of APP was considered to be able to target the cell membrane $\mathrm{e}^{10,11}$ and it is also a key fragment ${ }^{12}$ of $\mathrm{A} \beta 42$, dominating its aggregation. It is therefore a good candidate to be explored for the assembling mechanism, modulating the mechanism of assembled structure and the interaction with liposome. Many efforts have been made to explore the modulation of the formation of amyloid aggregates ${ }^{13}$. Many agents have been introduced for the modulation of amyloid peptide assembly $^{13,14}$. Recently, it has been reported that carbon nanotubes and fullerenes have strong inhibitory effect on amyloid aggregation ${ }^{15-19}$. As a promising and emerging carbon nanomaterial, graphene has also received much attention. Importantly, it provides opportunities for biological applications such as drug delivery $^{20-22}$, tissue engineering ${ }^{23,24}$, and a promising platform for the development of biosensors $^{25-31}$. Furthermore, intrinsic graphene is lipophilic. Chemical modified graphene can tune the hydrophilic and lipophilic properties of graphene to control the interactions with biological membranes ${ }^{32-34}$. Therefore, considering the improvement of solubility, biocompatibility and selectivity of GO, provides the possibility to modulate the assembled nanostructure of amyloid peptides because GO is considered to have good affinity to bind peptides ${ }^{39}$. The recent experimental and simulation studies have presented that GO can modulate the amyloid peptide fibrillation in solution $^{35-39}$. Therefore, it is implied that GO are significant nanomaterials for tuning amyloid peptide aggregation.

Atomic force microscopy (AFM) is capable of obtaining nanoscale resolution of 
individual molecules or supermolecular structures. This method also allows for the investigation of the self-assembly mechanism and the driving forces of

aggregation $^{40-44}$. Furthermore, AFM provides the possibility to follow the dynamics to obtain a detailed picture of the amyloid assembly process ${ }^{45}$, and the interaction between the liposome and peptides.

In this study, we acquired images of plain GO. We then imaged its mixture with amyloid peptide. Formed assemblies and their varying morphologies were revealed using AFM. We continued AFM investigation by tuning the GO concentration which, as proposed, resulted in alteration of the structure and activity of amyloid peptide assemblies. To further our understanding of amyloid peptides structural change we conducted circular dichroism experiments. Our results indicate that it is possible to change the structure of amyloid peptide assemblies by modulating it with GO. To this end, we formed liposome particles and measured the membrane disruption of amyloid peptide assemblies with and without GO modulation. We interpreted the morphological change in the liposome particles as a change in membrane disruption of amyloid peptide-GO assemblies.

\section{Experimental Sections}

\subsection{Material}

A 333-42 (amino acid sequence: NH2-GLMVGGVVIA-COOH) was purchased from ABBiochem Co. Ltd (Shanghai, China). Graphene oxide was purchased from XFNANO Materials Tech Co. Ltd (Nanjing, China). 1,1,1,3,3,3-Hexafluoro-2-propanol (HFIP) was purchased from Tokyo Chemical Industry (Tokyo, Japan). Polyvinylpyrrolidone (PVP) was purchased from Aladdin Industrial Corporation (Shanghai, China). Soy Lecithin, Cholesterol, Ethanol, Sodium phosphate dibasic anhydrous, Chloroform and Potassium dihydrogen phosphate were purchased from Sinopharm Chemical Reagent Co. Ltd (Shanghai, China).

\subsection{Synthesis of liposome}

Firstly, a mixture of $1 \mathrm{~g}$ of Lecithin and $0.2 \mathrm{~g}$ cholesterol was dissolved in $50 \mathrm{ml}$ chloroform under ultrasonic conditions and then transferred to a round-bottom glass 
flask. The solvent was then evaporated in a rotary evaporator (SY-2000, Yarong, Shanghai, China) at room temperature and a thin film of lipid formed on the wall of the flask. The flask was transferred to a Vacuum Drying Oven (DZF-6050, Jing Hong, Shanghai, China) for 24 hours at $60^{\circ} \mathrm{C}$ to get rid of the rest of the organic solvent. $0.05 \mathrm{~g}$ PVP was dissolved in a phosphate buffer solution under sonication $(\mathrm{pH}=7.2)$. This buffer solution used to hydrate the lipid film at room temperature (sonication) with the final concentration of the lipid was $10 \mathrm{mM}$. Multilamellar liposomes (MLV) were formed by vortexing for $4 \mathrm{~min}$ in a vortex mixer (Vortex-Genie 2, Scientific Industries, USA） followed by 30 minutes of sonication in a Transsonic Digitals bath sonicator (Elma, Germany), the sonicator was set to 10 seconds working followed by a 5 second break, with a power output of $360 \mathrm{~W}$. The resultant product was centrifuged at $6000 \mathrm{rpm}$ for 15 minutes. The supernatant was extruded through a filter with $0.22 \mu \mathrm{m}$ pore size to obtain the final liposome.

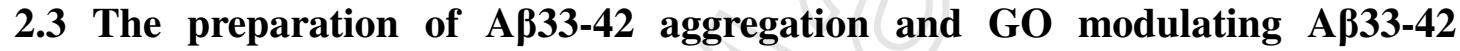
aggregation

$1 \mathrm{mg}$ A $333-42$ powder was dissolved in $1 \mathrm{ml}$ 1,1,1,3,3,3-Hexafluoro-2-propanol(HFIP), with 5 seconds ultra-sonication followed by 5 seconds of vortex mixing. Sonication and vortexing were repeated 6 times. The solution was put in a thermo-shaker (PHMT, Grant Instruments, UK) for 8 hours at $350 \mathrm{rpm}$ at $25^{\circ} \mathrm{C}$, to ensure that peptides powder had been fully dissolved. $100 \mu \mathrm{l}$ of A $333-42$ solution was transferred into a $1.5 \mathrm{ml}$ centrifuge tube, and sealed with parafilm. The tube was put in a Vacuum Drying Oven for 1 hour at $25^{\circ} \mathrm{C}$. After that, the HFIP was fully evaporated and a thin film of peptide formed on the bottom of tube. $200 \mu \mathrm{l}$ Milli-Q water was added to the dessicated-film tube, the solution was sonicated for 5 seconds and vortexed for 5 seconds (repeated 6 times) until the solution became clear. The A $333-42$ peptides monomer solution with a final concentration of $500 \mu \mathrm{M}$ prepared. The A $333-42$ peptides aggregated into intermediates with a final concentration of $500 \mu \mathrm{M}$ after 1 hour incubation. The A 333-42 peptides aggregated into fibers with a final concentration of $500 \mu \mathrm{M}$ after 6 hour incubation. 
Then the peptide solution was mixed with several different concentrations of GO in 1:1 ratio (v/v) at room temperature. The A $333-42$ concentration was $500 \mu \mathrm{M}$ and GO concentration was $5 \mu \mathrm{g} / \mathrm{mL}$ and $80 \mu \mathrm{g} / \mathrm{mL}$. The mixed solutions were incubated for 24 hours on a thermo-shaker at $350 \mathrm{rpm}$ and $37^{\circ} \mathrm{C}$.

\subsection{Atomic Force Microscopy Analysis}

$250 \mu \mathrm{L}$ prepared liposome solution was diluted with $250 \mu \mathrm{L}$ Milli-Q water in a $1.5 \mathrm{~mL}$ centrifuge tube and $300 \mu \mathrm{L}$ complex solution was added. This was mixed on a thermo-shaker for 6 hours at $350 \mathrm{rpm}$ and $37^{\circ} \mathrm{C} .10 \mu \mathrm{L}$ of the sample solution (the A 333-42 interimediate and fiber solution, the complex solution) were deposited on freshly cleaved mica for $10 \mathrm{~min}$, after that the residue liquid on the surface was removed. The sample was rinsed 3 times with Milli-Q water and dried in air before the measurement. All AFM measurements were performed in air using a commercial Asylum Research MFP-3D-SA (Asylum Research, Santa Barbara, California, USA) in tapping mode with an ultra-sharp silicon cantilevers (OMCL-AC160TS-R3, Olympus). Cantilevers had a nominal spring constant of $26 \mathrm{~N} / \mathrm{m}$ and a normal tip radius of $15 \mathrm{~nm}$. The resonant frequency was tuned to be $300 \mathrm{kHz}$ in all measurements and a scan frequency was set at $1 \mathrm{~Hz}$ with optimized feedback parameters. The resolution of all the original AFM images was 512 x 512 pixels per image.

\subsection{Secondary structural changes measured by circular dichroism spectroscopy}

The solution of control A $\beta 33-42$ peptide, as well as the complex solutions with GO concentration at $5 \mu \mathrm{g} / \mathrm{mL}$ and $80 \mu \mathrm{g} / \mathrm{mL}$ is characterized by Circular Dichroism (CD). CD measurements were performed on a Spectropolarimeter (PTC-348W1, JASCO, Hachioji City, Japan). The spectral region from $190 \mathrm{~nm}$ to $250 \mathrm{~nm}$ was scanned with a scan speed of $100 \mathrm{~nm} / \mathrm{min}$, with a path length of $0.1 \mathrm{~cm}$ and a slit-width of $2 \mathrm{~nm}$. All experiments were carried out at $25^{\circ} \mathrm{C}$ in a $1-\mathrm{mm}$ quartz cuvette. For each sample, the baseline, the signal of Milli-Q water, was subtracted from all measurement results. The sample volume for $\mathrm{CD}$ measurement is $350 \mu \mathrm{L}$. The concentration of control peptide and the one in the complex was both $250 \mu \mathrm{M}$.

\subsection{Raman spectroscopy}


Raman measurements were performed by using a laser Raman spectrometer

(DXR, Thermo Fisher, USA) at a wavelength of $532 \mathrm{~nm}$. The laser power was set at $10 \mathrm{~mW}$ and a $50 \mathrm{X}$ objective lens was used to focus the laser beam on the sample.

\section{Results \& Discussion}
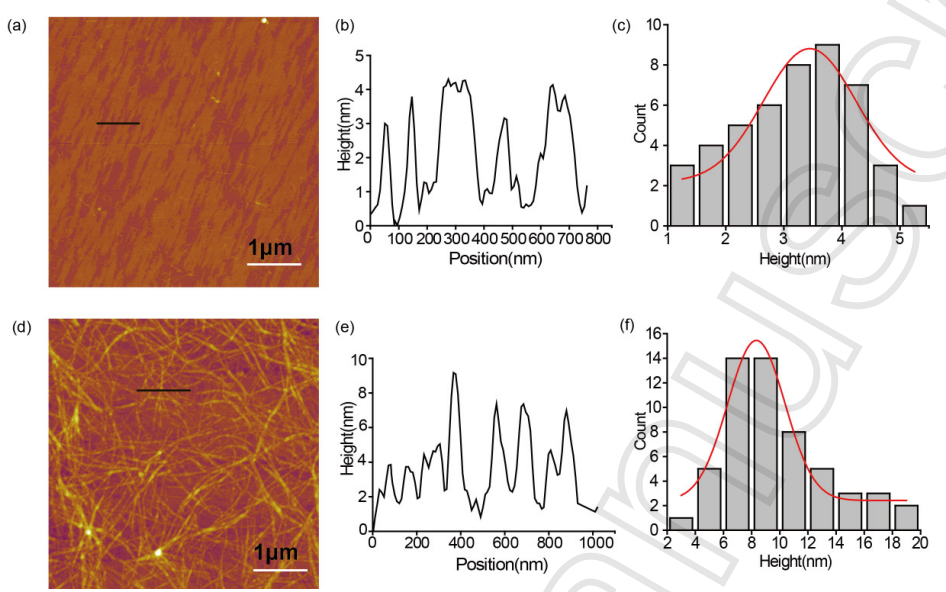

Figure 1 The AFM images of the intermediates and the fibrils assembled from A $\beta 33-42$. (a) Intermediates assembled from A $\beta 33-42$. (b) Height line profile of intermediates. (c) The histogram distribution of the height of the intermediates. (d) Fibrils assembled form AB33-42. (e) Height line profile of amyloid fibirls. (f) The height histogram distribution of amyloid fibrils.

Previously, it has been reported that A $\beta 33-42$ can self-assemble from monomer state to amyloid fibrils in a linear fashion with an exponential growth ${ }^{46}$. A $\beta 33-42$ tends to form $\beta$-sheet conformation initially, and gradually assembles into intermediates, and further into fibrils, which follows a typical nucleation-growth process $^{47}$. We obtained the intermediates and mature amyloid fibrils by incubating A $333-42$ with short time and long time intervals, respectively. Figure.1a and 1d show the AFM images of the intermediates and the fibrils. The intermediates which had been incubated for 1 hour at $37^{\circ} \mathrm{C}$ were determined to be the amyloid films with the height $3.4 \pm 0.8 \mathrm{~nm}$ (Figure.1b and 1c). Figure 1d shows amyloid fibrils which have been incubated for 6 hours at $37^{\circ} \mathrm{C}$. The height of the mature fibrils assembled from A $333-42$ was measured to be $8.3 \pm 2.0 \mathrm{~nm}$ (Figure.1e), and the histogram distribution was presented in Figure.1f. The morphology and height distribution of the intermediates and mature fibrils assembled from A $333-42$ display a clear difference. 

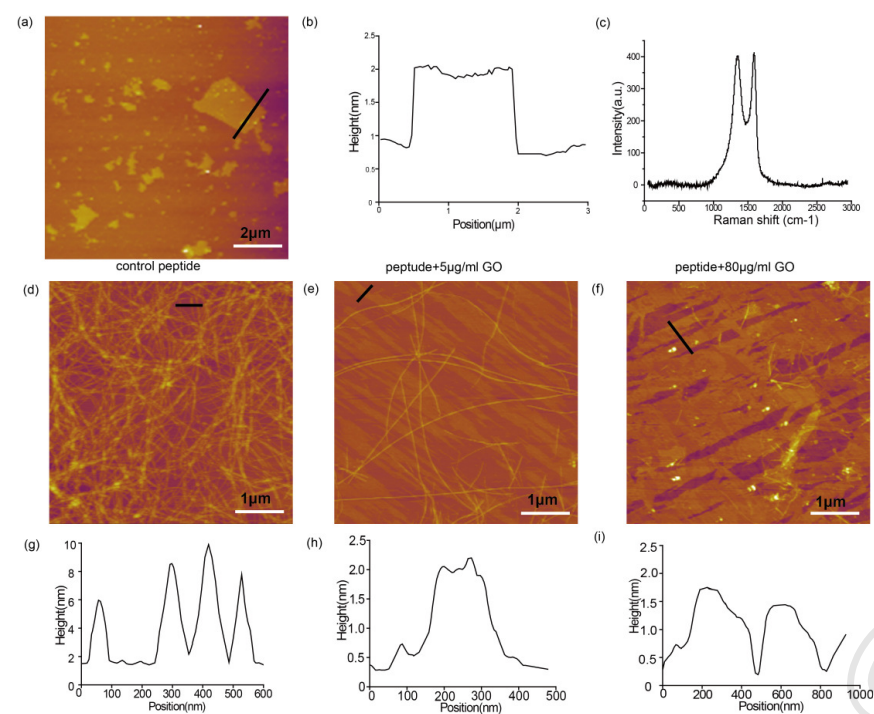

Figure 2 The AFM images of the effect of Graphene oxide (GO) modulating the A $333-42$ assembly. (a) the AFM image of graphene oxide. (b) Height line profiles of graphene oxide. (c) the Raman spectra of graphene oxide.(d) the AFM image of self-assembled amyloid fibrils without GO. (e) the AFM image of the assembled nanostructure of peptides modulated by GO with the concentration of $5 \mu \mathrm{g} / \mathrm{ml}$. (f) the AFM image of the assembled nanostructure of peptides modulated by GO with the concentration of $80 \mu \mathrm{g} / \mathrm{ml}$. (g)-(i) Height line profiles of assembled nanostructure of peptides, peptide modulated by GO with the concentration of $5 \mu \mathrm{g} / \mathrm{ml}, 80 \mu \mathrm{g} / \mathrm{ml}$ respectively.

Graphene oxide is used as the material to modulate assemblies of amyloid peptides. The morphology of GO is characterized by AFM and the height was measured to be $\sim 1 \mathrm{~nm}$ (Figure $2 \mathrm{a}$ and $2 \mathrm{~b}$ ). The Raman spectra shows the typical feature of GO (Figure. 2c). GO can modulate the assembly of amyloid peptide, which was proved by AFM. In the absence of GO, A $333-42$ can self-assemble into long and entangled mature fibrils with the height of $\sim 8 \mathrm{~nm}$ (Figure $2 \mathrm{~d}$ ). In the presence of GO with the concentration of $5 \mu \mathrm{g} / \mathrm{mL}$, the short fibrils were observed and also the mature ones existed but with a decreased amount. Meanwhile, flat films were observed (Figure 2e). When the concentration of GO reached to $80 \mu \mathrm{g} / \mathrm{mL}$, only flat films with uniform height $(\sim 1.5 \mathrm{~nm})$ were observed without mature fibrils (Figure $2 \mathrm{f})$. The morphology difference explored by AFM revealed the modulating effect of GO on self-assembled nanostructures of amyloid peptides, which implied that the large available surface of GO can tune the assembling process of amyloid peptide. 


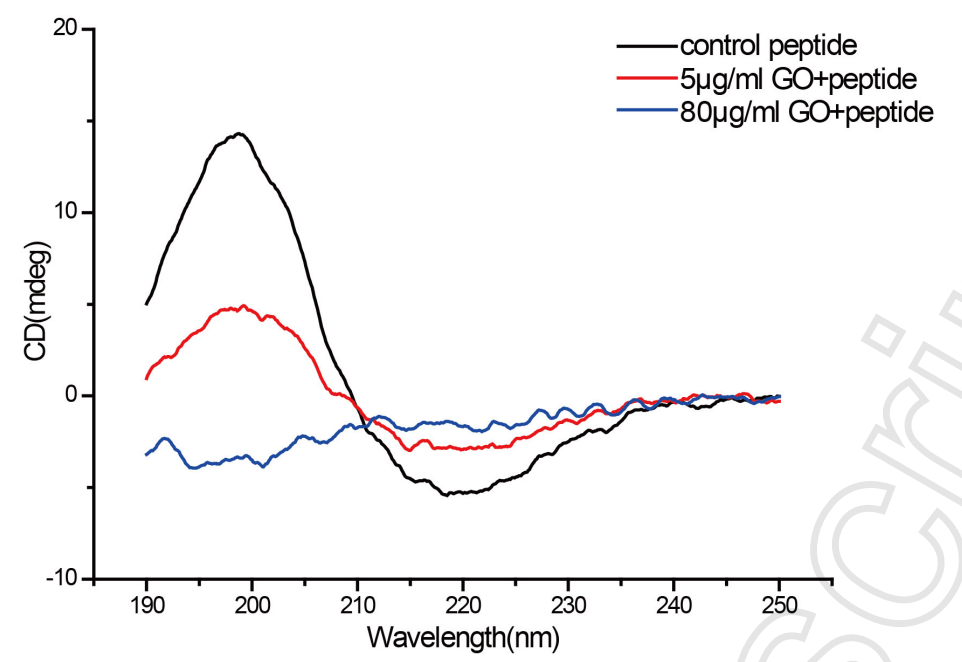

Figure 3 The secondary structure of amyloid peptide characterized by CD spectra. The $\beta$-sheet secondary structure was displayed in black line. The secondary structure of amyloid peptide in the presence of GO with the concentration of $5 \mu \mathrm{g} / \mathrm{mL}$ (red line) and $80 \mu \mathrm{g} / \mathrm{mL}$ (blue line).

In addition, we investigated the secondary structure of the amyloid peptide in the presence of GO by CD spectra in Figure 3. We can easily found that in the absence of $\mathrm{GO}$, the secondary structure of A $\beta 33-42$ is typically $\beta$-sheet. However, with increasing amount of $\mathrm{GO}$, from $5 \mu \mathrm{g} / \mathrm{mL}$ to $80 \mu \mathrm{g} / \mathrm{mL}$, the feature of curve remained the same but with decreased intensity. It is implied that the content of $\beta$-sheet of amyloid peptide might decrease in the modulation of GO. The further modulated effect on the interaction between the liposome and the assembled nanostructure of Aß33-42 modulated by GO were investigated.
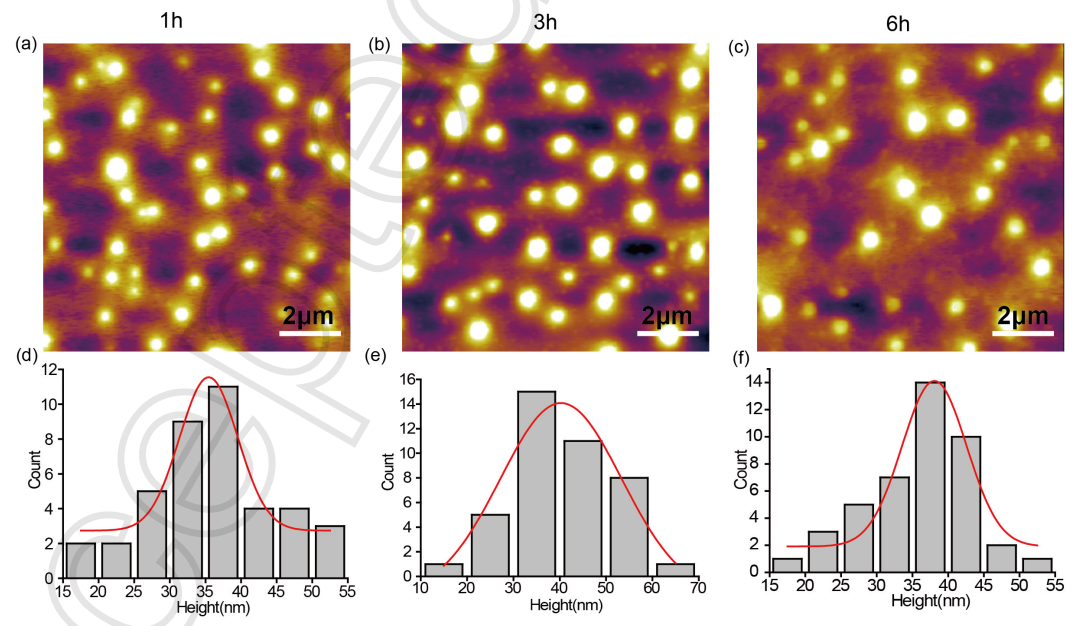

Figure 4. The morphology of liposome was characterized by AFM on mica in ambient condition, with different storage time 1 hour (a), 3 hour (b) and 6 hour (c).The height histograms of dried liposomes on mica with different storage time 1 hour (d), 3 hour (e), and 6 hour (f).

To obtain an insight into the interaction of liposome with modulated aggregates of amyloid peptides, the morphologies of liposomes with the assembled structure of 
peptides modulated by GO were explored. The morphology of as-prepared liposomes was characterized by AFM initially (Figure. 4). The pure liposome is stable without apparent changes in the morphology and the height of dried liposome was determined to be $\sim 40 \mathrm{~nm}$ on mica surface from 1 hour to 6 hour storage. Although it is not the original liposome structure as dried one on mica in ambient condition, it could be repeatable with no changing in the PBS buffer solution without other agents. It could be considered as the reference when the liposome was disrupted. The dried liposome structure should be different while the liposome was disrupted. Figure 5 presents the morphology difference of liposome and liposome with the modulated assembled structure of amyloid peptide by GO. The size of dried liposomes in the presence of the modulated assembled structure of amyloid peptide by GO is much smaller than the normal one without any agents. The morphologies and the height histograms of liposomes and interrupted liposomes were displayed. The liposome structures in the presence of modulated peptide aggregates with different incubation time were investigated. The average height was measured to be $35.4 \pm 4.1 \mathrm{~nm}$ for normal dried liposome in 1 hour incubation, $16.2 \pm 5.2 \mathrm{~nm}$ for the liposome with the peptides/GO $(5 \mu \mathrm{g} / \mathrm{mL})$ and $14.8 \pm 4.7 \mathrm{~nm}$ for liposome with the peptides/GO $(80 \mu \mathrm{g} / \mathrm{mL})$ both in 1 hour incubation. In the case of 3 hour incubation and 6 hour incubation, the structures of disrupted liposomes were shown in Figure 5h, 5i, 56n and 5o. The average heights of liposomes were measured to be $20.8 \pm 6.6 \mathrm{~nm}$ and $17.5 \pm 4.3 \mathrm{~nm}$ in case of 3 hour incubation, with the comparison of the heights of liposomes $(26.2 \pm 5.1 \mathrm{~nm}$ and 23.0 $\pm 1.1 \mathrm{~nm}$ ) in the case of 6 hour incubation. Generally, the liposome with the modulated peptide aggregates shrank further. 


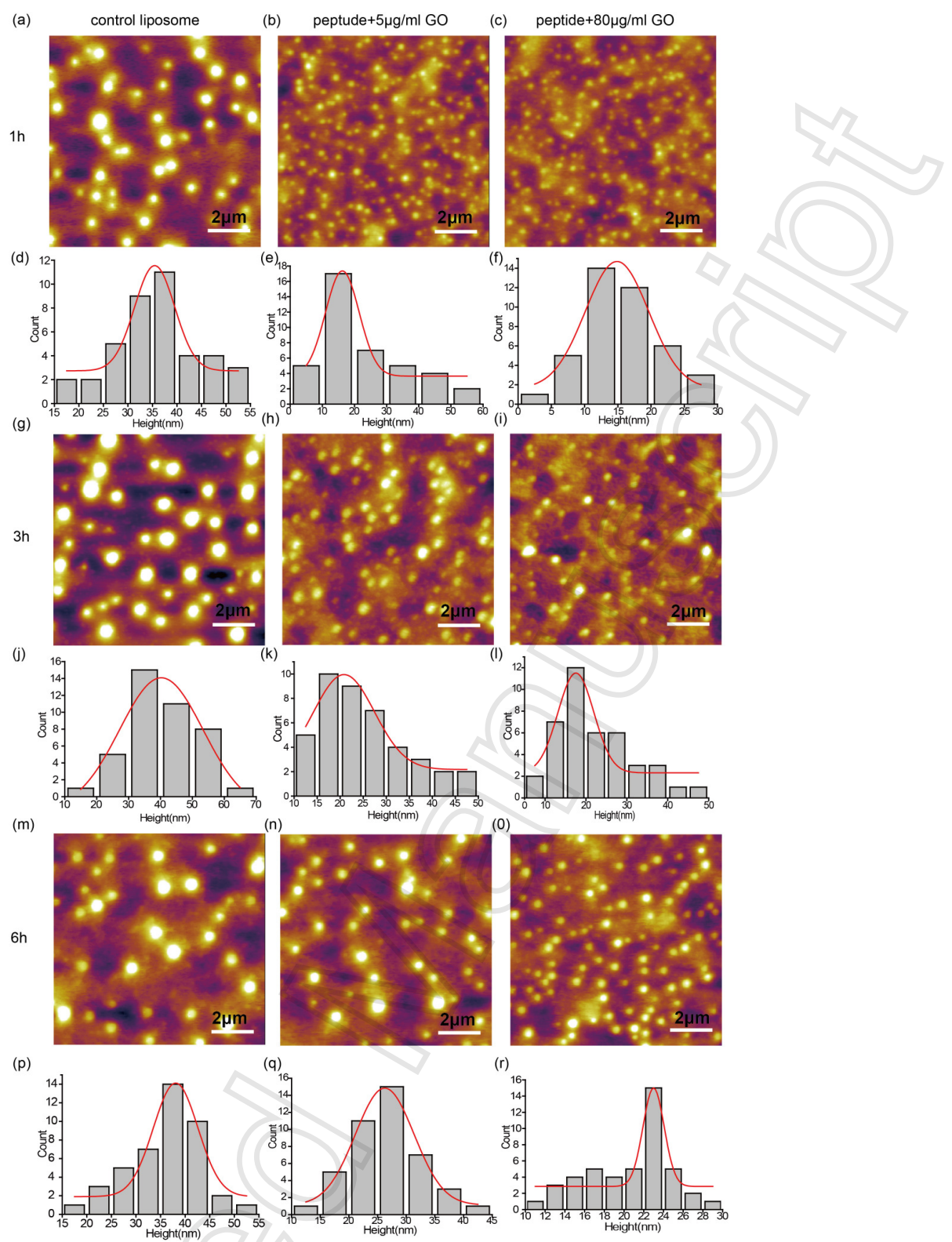

Figure 5 The morphologies and height distributions of liposome with the complex of GO and peptide in different incubation time characterized by AFM. (a-c, g-i, m-o) AFM images of dried liposomes and the liposome with the complex of peptide and GO $(5 \mu \mathrm{g} / \mathrm{mL}$ and $80 \mu \mathrm{g} / \mathrm{mL})$ for incubating 1 hour, 3 hour, and 6 hour, respectively. (d-f, j-1 and p-r) The height distributions of liposome, and liposome with the complex of peptide and GO $(5 \mu \mathrm{g} / \mathrm{mL}$ and $80 \mu \mathrm{g} / \mathrm{mL})$ for incubating 1 hour, 3 hour, and 6 hour, respectively.

The summary and the comparison of the size of liposomes were presented in Figure.6 both in the absence of the peptides/GO and in the presence of the peptides/GO. The clear difference was displayed. It is easy to find that the size of dried liposome decreased with increasing the amount of GO in the modulated assemblies of amyloid peptides. We could deduce that the increment of GO in the modulating assembled nanostructures of amyloid peptides could enhance the ability of 
membrane interaction. It is certificated by the liposome structure investigation. The exact mechanism of membrane disruption of modulated peptide assembled nanostructures is still unclear. Some possible mechanism was proposed to be the synergistic effect of amyloid peptide aggregate and GO. It is reported that GO are capable of extracting the phospholipid molecules in the previous research ${ }^{33}$. The amyloid peptide could also have the good affinity to the membrane. The modulated structures of amyloid peptides are almost flatten film which is the similar one to the intermediates of peptides that could be relative strong ability to interrupt the membrane. To sum up, the complex of amyloid peptide and GO might have the enhanced ability to the membrane interruption.

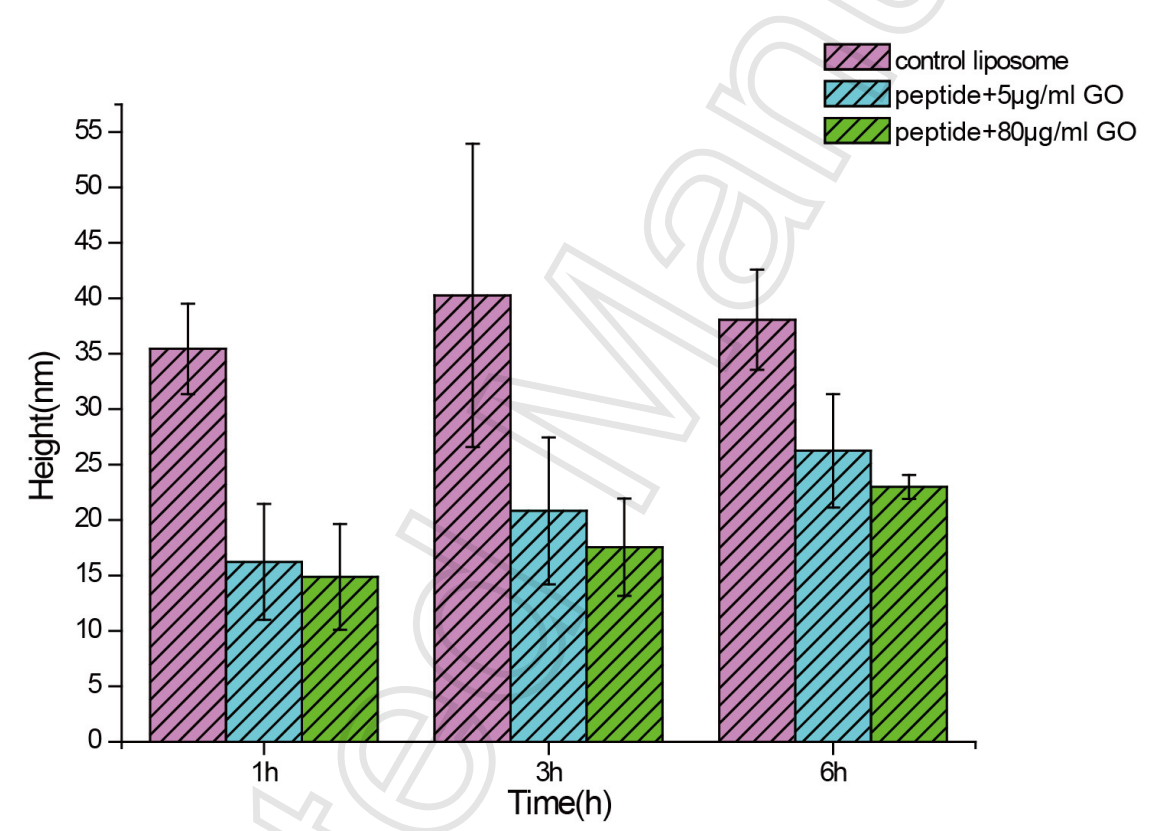

Figure 6. The height contrast of the liposome, the complex of liposome with peptide/GO at the concentration of $5 \mu \mathrm{g} / \mathrm{mL}$ and $80 \mu \mathrm{g} / \mathrm{mL}$ for GO in different incubation time, $1 \mathrm{~h}, 3 \mathrm{~h}$ and $6 \mathrm{~h}$, respectively. The height of liposome was obtained from AFM results.

\section{Conclusion}

In summary, the modulation effect of GO on the assembled structure of amyloid peptides was explored. The different nanostructures were obtained by tuning the concentration of GO. It is achieved that the membrane disruption of amyloid peptide aggregates could be modulated by GO. With GO's changing concentration we observed small fibrils, aggregates, intermediates and film like assemblies. Their 
contribution to total toxicity was investigated by lipid membrane disruption study -which was conducted using AFM. We believe our findings would contribute to understanding of amyloid peptide's pathogenesis and toxicity and its environmental effects. They can also be applied to studies where introduction and tuning of the structural control is needed.

\section{Acknowledgements}

This work was supported by Youth Natural Science Foundation of Jiangsu Province (Grant number: BK20140528, BK20140013) and the Jiangsu University research foundation (Grant number: 14JDG021). This work was also supported by Jiangsu Planned Projects for Postdoctoral Research Funds (1401068B), Jiangsu Specially Appointed Professor grant and Jiangsu University Funds (14JDG061, 11JDG098). Financial support from Institute for Advanced Materials, Jiangsu University is also gratefully acknowledged.

\section{References}

[1]S. M. Butterfield and H. A. Lashuel, Amyloidogenic protein-membrane interactions: mechanistic insight from model systems, Angewandte Chemie International Edition, 49(33):5628-5654(2010).

[2]G. G. Glenner, D. Ein, E. D. Eanes, H. A. Bladen, W. Terry and D. L. Page, Creation of "amyloid" fibrils from Bence Jones proteins in vitro, Science, 174(4010):712-714 (1971).

[3]G. G. Glenner, Amyloid deposits and amyloidosis. The $\beta$-fibrilloses, The New England Journal of Medicine, 302(23), 1333-1343 (1980).

[4]S. J. Soscia, J. E. Kirby, K. J. Washicosky, S. M. Tucker, M. Ingelsson, B. Hyman, M. A. Burton, L.E. Goldstein, S.Duong, R. E. Tanzi and R. D. Moir, The Alzheimer's disease-associated amyloid $\beta$-protein is an antimicrobial peptide, PIOS ONE, 5(3): e9505(2010).

[5]E. D. Roberson and L. Mucke, 100 years and counting: prospects for defeating Alzheimer's disease, Science, 314(5800): 781-784 (2006).

[6]D. L. Brody, S. Magnoni, K. E. Schwetye, M. L. Spinner, T. J. Esparza, N. Stocchetti, G. J. Zipfel and D. M. Holtzman, Amyloid- $\beta$ dynamics correlate with neurological status in the injured human brain, Science, 321(5893): 1221-1224 (2008).

[7]E. Mikros, D. Benaki, E. Humpfer, M. Spraul, S. Loukas, C. I.Stassinopoulou and M. Pelecanou, High-Resolution NMR Spectroscopy of the $\beta$ - Amyloid (1-28) Fibril Typical for Alzheimer's Disease, Angewandte Chemie-International Edition, 40(19):3603-3605(2001).

[8]M. S. R. Shearman, C. I. Ragan and L. L. Iversen, Inhibition of PC12 cell redox activity is a specific, early indicator of the mechanism of beta-amyloid-mediated cell death, Proc. Natl. Acad, Sci. U.S.A., 91(4): 1470-1474(1994).

[9]L. Liu, L. Zhang, L. Niu, M. Xu, X. B. Mao, Y. L. Yang and C.Wang, Observation of reduced cytotoxicity of aggregated amyloidogenic peptides with chaperone-like molecules, ACS Nano, 5(7): 6001-6007(2011).

[10]J. Herms, C. Priller, T. Bauer, G. Mitteregger, B. Krebs and H. A.Kretzschmar, Synapse 
formation and function is modulated by the amyloid precursor protein, Journal of Neuroscience, 26(27): 7212-7221 (2006).

[11]D. J. Selkoe, Physiological production of the $\beta$-amyloid protein and the mechanism of Alzheimer's disease, Trends in Neurosciences, 16(10): 403-409 (1993).

[12]L. Liu, L. Zhang, X. B. Mao, L. Niu, Y. L. Yang and C. Wang, Chaperon-mediated single molecular approach toward modulating $A \beta$ peptide aggregation, Nano Letters, 9(12):4066-4072(2009).

[13]M. Zhang, X. Mao, Y. Yu, C. X. Wang, Y. L. Yang and C. Wang, Nanomaterials for reducing amyloid cytotoxicity, Advanced Materials, 25(28):3780-3801(2013).

[14]C. Li and R. Mezzenga, The interplay between carbon nanomaterials and amyloid fibrils in bio-nanotechnology,Nanoscale, 5(14): 6207-6218 (2013).

[15]J. E. Kim and M. Lee, Fullerene inhibits $\beta$-amyloid peptide aggregation, Biochem. Biophys. Res. Commun., 303(2):576-579(2003).

[16]H. Li, Y. Luo, P. Derreumaux and G. Wei, Carbon nanotube inhibits the formation of $\beta$-sheet-rich oligomers of the Alzheimer's amyloid- $\beta$ (16-22) peptide, Biophysical Journal, 101(9):2267-2276(2011).

[17]Z. Fu, Y. Luo, P. Derreumaux and G. Wei, Induced $\beta$-Barrel Formation of the Alzheimer's A 25-35 Oligomers on Carbon Nanotube Surfaces:Implication for Amyloid Fibril Inhibition, Biophysical Journal, 97(6): 1795-1803(2009).

[18]A. K. Jana and N. Sengupta, Adsorption Mechanism and Collapse Propensities of the Full-Length, Monomeric A $\beta$ 1-42 on the Surface of a Single-Walled Carbon Nanotube: A Molecular Dynamics Simulation Study Biophysical Journal, 102(8): 1889-1896(2012).

[19]A. K. Jana, J. C. Jose and N. Sengupta, Critical roles of key domains in complete adsorption of $\mathrm{A} \beta$ peptide on single-walled carbon nanotubes: insights with point mutations and MD simulations, Phys.Chem. Chem. Phys, 15(3): 837-844 (2013).

[20]V. C. Sanchez, A. Jachak, R. H. Hurt and A. B.Kane, Biological interactions of graphene-family nanomaterials: an interdisciplinary review, Chem. Res. Toxicol, 25(1): 15-34(2011).

[21]L. Feng and Z. Liu, Graphene in biomedicine: opportunities and challenges, Nanomedicine ,6(2): 317-324(2011).

[22]Z. Liu, J. T. Robinson, X. Sun and H. Dai, PEGylated nanographene oxide for delivery of water-insoluble cancer drugs, Journal of the American Chemical Society, 130(33): 10876-10877(2008).

[23]Y. Zhang, T. R. Nayak, H. Hong and W. Cai, Graphene: a versatile nanoplatform for biomedical applications, Nanoscale, 4(13): 3833-3842(2012).

[24]S. K. Lee, H. Kim, B. S. Shim, Graphene: an emerging material for biological tissue engineering ,Carbon Letters, 14(2):63-75 (2013).

[25] H. Wang, Q. Zhang, X. Chu, T. Chen, J. Ge and R. Yu, Graphene oxide-peptide conjugate as an intracellular protease sensor for caspase-3 activation imaging in live cells, Angew.Chem. Int. Ed. 50(31): 7065-7069 (2011).

[26]J. Balapanuru, J.X. Yang, S.Xiao, Q. Bao, M. Jahan, L. Polavarapu, J. Wei, Q. H. Xu and K. P. Loh, A Graphene Oxide-Organic Dye Ionic Complex with DNA - Sensing and Optical - Limiting Properties ,Angewandte Chemie, 122(37): 6699-6703(2010).

[27]C.H. Lu, H. H.Yang, C. L. Zhu, X. Chen and G.N. Chen, A graphene platform for sensing 
biomolecules, Angewandte Chemie, 121(26): 4879-4881 (2009).

[28]H. Jang, Y. K. Kim, H. M. Kwon, W. S. Yeo, D. E.Kim and D.H. Min, A Graphene-Based Platform for the Assay of Duplex - DNA Unwinding by Helicase, Angewandte Chemie, 122(33): 5839-5843(2010).

[29]J. H.Jung, D. S. Cheon, F. Liu, K. B. Lee and T. S. Seo, A Graphene Oxide Based Immuno-biosensor for Pathogen Detection, Angew. Chem. Int. Ed, 49(33):5708-5711(2010).

[30]X. Wang, C. Wang, K. Qu, Y. Song, J.Ren, D. Miyoshi, N. Sugimoto and X. Qu, Ultrasensitive and Selective Detection of a Prognostic Indicator in Early-Stage Cancer Using Graphene Oxide and Carbon Nanotubes, Advanced Functional Materials, 20(22):3967-3971 (2010).

[31]M. Zhang, B. C. Yin, X. F. Wang and B. C. Ye, Interaction of peptides with graphene oxide and its application for real-time monitoring of protease activity, Chemical Communications, 47(8):2399-2401 (2011).

[32]K. S. Novoselov, V.I. Fal'ko, L. Colombo, P. R. Gellert, M. G. Schwab and K. Kim, A roadmap for graphene, Nature, 490(7419): 192-200 (2012).

[33] Y. Tu, M. Lv, P. Xiu, T. Huynh, M. Zhang, M. Castelli, Z. Liu, Q.Huang, C. Fan, H. Fang and R. Zhou, Destructive extraction of phospholipids from Escherichia coli membranes by graphene nanosheets, Nature nanotechnology, 8(8): 594-601 (2013).

[34]Y. Li, H. Yuan, A. von dem Bussche, M. Creighton, R. H. Hurt, A. B.Kane and H. Gao, Graphene microsheets enter cells through spontaneous membrane penetration at edge asperities and corner sites, Proceedings of the National Academy of Sciences, 110(30): 12295-12300(2013).

[35]T. Kowalewski and D. M. Holtzman, In situ atomic force microscopy study of Alzheimer's $\beta$-amyloid peptide on different substrates:New insights into mechanism of $\beta$-sheet formation, Proceedings of the National Academy of Sciences, 96(7): 3688-3693(1999).

[36]D. Losic, L. L. Martin, M. I. Aguilar and D. H. Small, $\beta$-Amyloid fibril formation is promoted by step edges of highly oriented pyrolytic graphite, Peptide Science, 84(5):519-526 (2006).

[37]R. Laghaei, N. Mousseau and G. Wei, Structure and thermodynamics of amylin dimer studied by hamiltonian-temperature replica exchange molecular dynamics simulations, J. Phys. Chem. B, 115(12): 3146-3154(2011).

[38]X. Yu, Q. Wang, Y. Lin, J. Zhao, C. Zhao and J. Zheng, Structure, orientation, and surface interaction of Alzheimer amyloid- $\beta$ peptides on the graphite, Langmuir, 28(16): 6595-6605(2012).

[39]M.Mahmoudi, O. Akhavan, M. Ghavami, F. Rezaee and S. M. A. Ghiasi, Graphene oxide strongly inhibits amyloid beta fibrillation, Nanoscale, 4(23), 7322-7325 (2012).

[40]P. Liu, S. Zhang, M. S .Chen, Q. Liu, C. Wang, Y. M. Li, F. Besenbacher and M. D. Dong, Co-assembly of human islet amyloid polypeptide (hIAPP)/insulin, Chem Commun, 48(2):191-193(2012).

[41]J. Adamcik, J. M. Jung, J. Flakowski, Paolo De Los Rios, G. Dietler and R. Mezzenga, Understanding amyloid aggregation by statistical analysis of atomic force microscopy images, Nat Nanotechnol, 5(6):423-428(2010).

[42]M. D. Dong, M. B. Hovgaard, S. L. Xu, D. E. Otzen and F. Besenbacher, AFM study of glucagon fibrillation via oligomeric structures resulting in interwoven fibrils, Nanotechnology, 17(16):4003-4009(2006).

[43]Y.P. Yu, S. Zhang, Q. Liu, Y. M. Li, C. Wang, F. Besenbacher and M. D. Dong, 2D amyloid aggregation of human islet amyloid polypeptide at the solid-liquid interface, Soft Matter, 
8(5):1616-1622(2012).

[44]A. Quist, I. Doudevski, H. Lin, R. Azimova, D. Ng, B. Frangione, B. Kagan, J. Ghiso and R. Lal, Amyloid ion channels: A common structural link for proteinmisfolding disease, Proc Natl Acad Sci USA, 102(30):10427-10432(2005).

[45]J.Adamcik, V. Castelletto, S. Bolisetty, I. W. Hamley and R. Mezzenga, Direct observation of time-resolved polymorphic states in the self-assembly of end-capped heptapeptides, Angew Chem Int Ed Engl, 50(24):5495-5498(2011).

[46]Q. Li, L. Liu, S. Zhang, M. Xu, X. Q. Wang, C. Wang, F. Besenbacher and M. D. Dong*, Modulating A $333-42$ Peptide Assembly by Graphene Oxide, Chemistry-A European Journal, 20(24): 7236-7240 (2014).

[47]E. Hellstrand, B. Boland, D. M. Walsh and S. Linse, Amyloid $\beta$-protein aggregation produces highly reproducible kinetic data and occurs by a two-phase process, ACS Chem.Neurosci., 1(1): 13-18(2009). 